HENRIK BERGQVIST (Stockholm University)

\title{
Epistemic marking and multiple perspective: An introduction ${ }^{1}$
}

This paper discusses forms of epistemic marking that instantiate multiple perspective constructions (see Evans 2005). Such forms express the speaker's and the addressee's simultaneous epistemic perspectives from the point of view of the speaker, crucially relying on the assumptions of the speaker with regard to the addressee's knowledge. The analysis of forms considers established semanto-pragmatic concepts, such as semantic scope, mitigation strategies and communicative intention (as marked by sentence-type) in the exploration of forms. In addition, the notion of knowledge asymmetry is discussed alongside the concepts of epistemic status and stance as tools for a semantic analysis of investigated forms.

\section{Introduction}

Human socio-cognitive abilities allow for a developed alignment of individual attentions and can be observed in our acute sensibility to what others think and believe; we keep track of (what we think) others know and their attitude towards certain events in shaping and maintaining strategies for everyday social interaction. From a communicative stand point, there is a basic need to identify interactive positions with respect to the "common ground" something that has long been realized in pragmatics and language psychology (CLARK 1996, inter alia). Linguistically, the common ground is part of the back-drop against which we make contextually sensitive, in-the-moment decisions about what information to present and how to present it. More narrowly, presupposition, definite reference and speech-acts are well-explored areas of research that share a preoccupation with how assumptions about the minds of others influence the way an utterance is packaged (cf. LEVINSON 1983; SEARLE 1969).

Beyond these areas, limited attention has been paid to how assumptions about the cognitive and mental states of others can be signaled by various grammatical resources and structures. The dominant strategy for investigating the properties of indexicals like person markers and markers of tense and mood has been to start from the point of view of a speaker-

1 This special issue results from the project, "Complex perspective in epistemic assessment: exploring intersubjectivity in language", funded by the Swedish Research Council (dnr. 20112274, Participants: HENRIK BERGQVIST, Stockholm University (PI), LILA SAN RoQUE, Max Planck Institute for Psycholinguistics, and Prof. NICHOLAS EVANS, Australian National University in Canberra). Three of the papers in this collection were originally presented at a oneday workshop (Complex perspective in epistemic marking: a workshop on the origins, motivations and definitions of intersubjective perspectives in grammar), held at the SLE 2012 conference in Stockholm on the $30^{\text {th }}$ of August 2012. Thanks to all the participants in the workshop, especially SONJA GIPPER, DAVID HARGREAVES, GWEN HySLOP, MATTI MiESTAMO, ZARINA MOLOCHIEVA, ERIKA SANDMAN, and ARIE VERHARGEN. Many thanks also to LILA SAN ROQUE who greatly contributed in the process of writing the present paper. The usual disclaimers apply. 
subject with limited regard for how an addressee (or a third party) may affect the speaker's subjective stance. In recent years, however, various descriptions explore the role of the addressee in analyzing evidentials and related epistemic marking strategies (e.g. LANDABURU 2007; SAN ROQUE 2008; HADDAD 2013). The possibility has also been raised that morphemes and constructions can encode multiple perspectives, allowing two coexisting perspectives to be related to each other and the narrated situation in different ways ("multiple perspective constructions", see EVANS 2005; Section 2, below).

The present volume constitutes a further exploration of how multiple perspectives are expressed in various forms of epistemic marking based on data from a small but diverse set of languages. Although the discussed forms have different origins and distributions in the languages where they occur, the majority share a function of modifying the communicative intentions of the speaker by specifying knowledge (a)symmetries between the speech participants.

Below, we introduce different grammatical resources for situating information with regard to the sometimes differing epistemic perspectives of the speech participants. We use the word 'perspective' in a fairly theory-neutral way to talk about a subjectively anchored relation to the propositional content of a clause or utterance; for example, a linguistic structure that expresses the speaker's point of view of an event or situation is said to encode the speaker's perspective under this use of the term. The use of the term 'epistemic' includes well-known categories, such as 'epistemic modality' and 'evidentiality' (the marking of information source), but also includes markers of broader knowledge-related domains such as 'newness'/'unexpectedness' (i.e. 'mirativity'), and less well-known phenomena such as 'engagement' (LANDABURU 2007) and 'complex epistemic perspective' (BERGQVIST forthcoming). We use the term 'marking' to denote structures that carry more functional than lexical load (e.g., inflections, clitics, auxiliaries, and particles) and that are more or less paradigmatic, with (at least) clausal scope.

\section{Perspective in epistemic marking}

As part of the exploration of perspective in epistemic marking, we briefly discuss the notions of 'viewpoint' and 'stance' in order to relate these to the notion of multiple perspective (see Section 2.1, below). A frequent use of viewpoint is in analyses of grammatical and lexical aspect; more specifically how the imperfective and perfective contrast signals differences in point of view from the speaker's perspective (cf. SMITH 1994; CAUDAL \& RoUSSAIRE 2005). Aspectual viewpoints in texts have also been described by HOPPER (1979) and FLEISCHMAN (1991) as part of narrative strategies. DANCYGIER \& SWEETSER (2012) take a "Mental Spaces" approach (FAUCONNIER 1985) to analyzing constructions that signal viewpoint as constituting part of the indexical configuration of the ground (i.e. the speaker's center of experience). They recognize the width of available linguistic devices for signaling viewpoint and the fundamental role that viewpoint plays in human affairs even outside of language. Two crucial observations bridge viewpoint to the notion of multiple perspective; firstly, that human language allows 
for embedding of viewpoints since the presence of another human imposes a second viewpoint on a human subject's primary point of view. Secondly, the authors recognize the role of the hearer in structuring the speaker's viewpoint, stating that it may be appropriate to define the concept of viewpoint from the simultaneous perspectives of the speech participants, rather than the speaker's isolated point of view (DANCYGIER \& SWEETSER 2012: 12).

While the notion of viewpoint is connected to work on aspect and tense, the term 'stance' is found more often in investigations of modality (e.g. Kockelman 2004) and evidentiality (MUSHIN 2001). A marker of stance is an expression of 'subjectivity' a notion that in of itself is both problematic and important for perspective-taking in grammar (e.g. BENVENISTE 1971 [1966]; LYONS 1977; TRAUGOTT 1989; TRAUGOTT \& DASHER 2002). Combining observations by JAKOBSON (1990 [1957]) and GOFFMAN (1981), KOCKELMAN (2004) discusses modal markers in Q'eqchi' Maya as an expression of the speaker's level of commitment to the reality of some event. Kockelman goes on to describe this expression of commitment as a "first-order" stance, but notes that speakers may also convey a "meta-stance", that is, display a position concerning (their own or another's) first order stance. The embedding of one subjective stance within another parallels the one mentioned above for viewpoint and leads us to a more detailed formulation of perspective and how multiple points of view may be accommodated in one and the same expression.

\subsection{Multiple perspective}

Conceptually, second-order stances and embedded viewpoints are directly comparable to certain kinds of multiple perspective constructions as defined by EvANS' (2005): that is, grammatical constructions that "encode potentially distinct values, on a single semantic dimension, that reflect two or more distinct perspectives or points of reference" (99). According to EVANS, multiple perspective constructions are found on different levels of grammar and include (at least) three logically possible kinds of perspective: double, meta- and complex perspective.

A double perspective is calculated directly with regard to some object of reference. A prototypical example of double perspective is found in demonstrative systems where both the speaker's and the addressee's positions in relation to a figure are salient parameters. In Japanese, there is a well-known contrast between kore ('this one') and sore ('that one') in terms of primary orientation towards the speaker (kore) or the addressee (sore; HINDS 1973:1). The form, are ('that one there') signals a removal from both the speaker and the addressee. Evans suggests that double perspective constructions are most likely limited to "transparent dimensions of experience" such as space and time, as these do not require calculations regarding the attention and psychological state of others (a feature of meta and complex perspective constructions, see below). That is, the stated perspectival values are to a large extent objectively verifiable. This being said, we note that demonstratives 
can do much more than indicate observable spatial relations, and these functions may indeed involve psychological and attentional parameters (see, e.g., BURENHULT 2003, ENFIELD 2003, HIMMELMANN 1996).

Meta- and complex perspective constructions feature the notional embedding of one perspective inside another. In meta-perspective constructions the perspective of one person is considered from the perspective of another. This can be exemplified by a reported evidential construction that is conceptually comparable to a (periphrastic) English example such as, "He said that Matilda lit the match". That is, the speaker asserts a report of another's assertion, but does not directly state an assertion regarding the second assertion, i.e. Matilda's action.

Complex perspective goes one step further in that it features both embedding and an assertion of two perspectives from the speaker's point of view, as in "Obviously, Matilda lit the match". In the context of the present paper, a meta-perspective is contrasted to a complex perspective with respect to the presence of 'commitment' in a form. A metaperspective does not require the speaker's commitment regarding the perspective of the other although it may be implied, usually in terms of an opposing commitment as in, "They say he's innocent" [implicature: I think he is guilty], or alternatively, by a weaker commitment to the proposition of the utterance. A complex perspective features an embedded perspective of another in which the commitment of the speaker is entailed. This perspective is signaled by forms such as obviously and of course, which feature the commitment of the speaker and the assumption that this is a commitment shared by the addressee (see SiMON-V ANDENBERGEN \& AIJMER 2007).

In epistemic marking, multiple perspective is exclusively used to refer to variants of meta- and complex perspective, given the necessary embedding of perspectives. In metaperspective, the 'invisible' knowledge state of one person (the non-speaker) is presented as ostensibly inferred from the point of view of another (the speaker). In complex perspective, this relationship also holds, but with the added feature of the speaker asserting their own view with respect to the proposition, as well as the addressee's view of the proposition. Multiple perspective in epistemic marking partially overlaps with the notions of viewpoint and stance, but with an increased focus on the different ways in which perspectives and viewpoints may be expressed, and what subsystems of language facilitate such expressions.

\subsection{Examples of multiple perspective in epistemic marking}

Expressions of multiple perspective in epistemic marking is found in different kinds of linguistic structures. The first examples that we discuss here are modal particles and sentence-type-like markers, items with wide scope that appear to function as modifiers of the speech-act, that is, at the illocutionary level or above. While a multiple perspective analysis may not be appropriate for all instances of such forms, it is argued that this concept is relevant in some languages, and that the primary function of these is to position the epistemic perspectives of the speech participants from the point of view of the speaker. 
Other forms have a seemingly more narrow scope, e.g. inflectional forms that may be grouped with evidentials and signal whether an event was witnessed by the speaker only, or collectively (i.e. by the speaker and the addressee). To close the section, we discuss some further issues concerning the semantics of epistemic markers in relation to addressee-oriented epistemic values as opposed to those that relate to a third party, or to forms that are unspecified in this regard.

Perhaps the most well-known and well-studied grammatical resource that is relevant to investigating epistemic aspects of multiple perspective are modal particles (see e.g. JACOBS 1991; KÖNIG et al. 1990; WALTEREIT 2001). Modal particles have mainly been described for Germanic languages with comparable research on Japanese and, to a lesser degree, Mandarin (cf. ABRAHAM \& LEISS 2012). Although not all modal particles in Germanic languages may be analyzed as signaling speaker-assumptions regarding the perspective of the addressee, several of them do just that. According to ABRAHAM \& LEISS (2012) modal particles allow the speaker to express "an estimate about the knowledge awareness of the [a]ddressee while letting the [a]ddressee know about this estimate [...]" (7). For a modal particle like the German $j a$, addressee-knowledge is an encoded feature of the form alongside with the speaker's certainty, something that has prompted researchers to view modal particles as markers of "twofold deixis" that accommodate the deictic center of the addressee as part of the referential ground (8). Comparable analyses apply to the cognate $j u$ in Swedish (Lindström 2008) and jo in Norwegian (ANDVIK 1992). Below is an example of $j u$ from Swedish:

$$
\begin{aligned}
& \text { M: dom har ju inte förstånd } \\
& \text { 3PL have MP not sensible } \\
& \text { att spänna kroppen } \\
& \text { to tense body.DEF } \\
& \text { '(Of course) They're not sensible enough to stiffen up (when they fall).' } \\
& \text { L: } \quad n \ddot{a} \text { men de } e \text { ju fulla människor } \\
& \text { neg but it is MP drunken people } \\
& \text { som faller } \\
& \text { that fall } \\
& \text { 'No, but (as you know) it's drunken people that do fall.' }
\end{aligned}
$$

\section{LINDSTRÖM (2008: 74 [my orthographic adjustments])}

Example (1) exemplifies how $j u$ is used to signal general knowledge, i.e. information that is locally accepted by many, including the speaker and the addressee. Modal particles are a specific kind of discourse particle that is used to manage and organize discourse from the narrator/speaker's perspective. They are non-obligatory, but frequent in spoken 
discourse and fall somewhere between the creative use of lexical resources to signal speaker-stance (e.g. of courselas you know) and more systematic morpho-syntactic means that serve the same function (compare to the examples from Kogi, below).

Related to research on modal particles is a recent study of the cross-linguistic properties of sentence final particles used to form polar interrogatives. ENFIELD et al. (2013) investigates sentence final particles (SFPs) in Dutch, Lao, and Tzeltal and propose an analysis of the semantics of these in terms of an "epistemic gradient" that positions the epistemic positions of the speaker and the addressee in an attempt to define the existing knowledge asymmetries found in a given particle. In the use of different forms, the epistemic gradient is "tilted" to signal the speaker's knowledge and the speaker's assumptions regarding the addressee's knowledge of the (incomplete) propositional content, or topic, of the polar question.

As in the case of modal particles, there is room for more than knowledge related assumptions regarding "who-knows-what". Attitudinal meaning, in terms of "level of expectation regarding a positive reply", as well as evidential components are also found in some of the investigated particles. ENFIELD et al. regard SPFs as formally akin to "statement interrogatives", thus closing the gap between SPFs and modal particles, which mainly occur in declarative contexts.

Sentence-type phenomena are relevant to the present investigation for at least two reasons. Firstly, it has been frequently observed that the formal marking of a sentence-type associated with a certain speech-act is used to signal a communicative intention that belongs to a contrasting speech-act, resulting in so called "indirect speech-acts", a concept that has been severely criticized (e.g. LEVINSON 1979). Declaratives that signal prototypical statements can be used as questions/requests and vice versa (cf. STIVERS 2010, who observes that "declarative questions" make up a majority of polar questions in American English). HERITAGE (2012) explores such discrepancies between sentencetype, by form, and the communicative intentions of the speaker (see HERITAGE 2012, 2013; HERITAGE \& RAYMOND 2005). He introduces two concepts in an effort to explain these, namely "epistemic status" and "epistemic stance". Epistemic status draws on the notion of A and B-events (LABOV \& FANSHEL 1977), where the former are within the domain of the speaker and the latter targets events that pertain to the addressee. Typical B-events include opinions and beliefs that are held by the addressee but also include instances of professional expertise as illustrated by doctor-patient interactions in which the doctor is entitled to make unqualified statements about the bodily state of the patient despite the private nature of bodily sensations (see also KAMIO 1997, who notes the ungrammaticality of Japanese statements that target the addressee's "territory of information", unless these are marked by appropriate sentence final particles, which serve to distance the speaker and weaken the force of such statements).

The speaker's epistemic stance, as signaled by the choice of sentence-type can be congruent or incongruent with his/her epistemic status depending on adherence to interpersonal considerations such as level of intimacy and power relations between the speech 
participants. The correlation between epistemic status and stance and the role of sentencetype in signaling a certain epistemic stance, suggests a function of declaratives and interrogatives as signals of the speech participant's asymmetric knowledge along with what is considered private or public.

Secondly, particles and morphemes used to signal (polar) questions often belong to paradigms that house markers of modality and evidentiality, something that puts into question the special status of sentence-type markers in such languages, by form. While it remains clear that there is such a thing as communicative intentions and that these can be linked to certain clause-level structures, it is not clear where the boundary between markers of sentence-type and those that are preferably analyzed as epistemic markers of some kind, is to be drawn. It would be problematic to analyze epistemic marking as signaling a certain sentence-type/speech-act, by default, but there is reason to recognize a certain amount of overlap between the two phenomena.

This situation can be exemplified with data from the Arwako-Chibchan language Ika, where there is a set of three sentence-type markers, $-i n,-e$, and - $o$ that also serve a function as epistemic markers by their capacity to signal "epistemic authority" (BERGQVIST 2012: 159). From a sentence-type perspective, -in may be regarded as 'declarative' and - $o$ as 'interrogative' with $-e$ as an inter-mediate form that has features of both, a feature that motivates a comparison to the already mentioned "statement interrogatives" from ENFIELD et al.'s investigation of SFPs (see above).

As a marker of epihstemic authority, -in encodes the speaker's authority, a feature that fits well with the default function of declaratives to provide the addressee with new information. The interrogative $-o$ encodes the addressee's authority, mapping onto the function of an interrogative marker, whereas $-e$ signals a common ground between the speaker and the addressee and may be analyzed as a form that encodes a shared authority between the speaker and the addressee. The examples below illustrate these semantic contrasts:

$$
\begin{array}{cll}
\text { a } & \begin{array}{l}
k a m-\partial n \\
\text { sleep-PARTC } \\
\text { 'I am asleep.' }
\end{array} & \begin{array}{l}
n u ́ k-w-i n \\
\text { be-EGO-SA }
\end{array} \\
& & \\
\text { b } & \begin{array}{l}
k a m-\partial n \\
\text { sleep-PARTC }
\end{array} & \text { 2SG-be-DIST-EGO-S/AA } \\
& \text { 'You are asleep (you look like you are)?' }
\end{array}
$$

(BERGQVIST 2012:171)

The examples in (2) are utterances that concern actions, which involve the speaker and the addressee, respectively, as indicated by subject person and egophoric marking. They may both be regarded as declarative despite the presence of a question mark in $(2 b)$; the 
interrogative connotation disappears when the second person subject is changed to first person as in $(3)^{2}$.

$$
\begin{aligned}
& \text { kama-k-w-e } \\
& \text { sleep-DIST-EGO-S/AA }
\end{aligned}
$$

'I slept (you remember).' (ELI_090823)

If the speaker-asymmetric marker -in is used to mark an utterance with a second person subject, the result resembles a hortative construction in which the speaker commands the addressee (or a third party) to perform an action:

$$
\begin{array}{ll}
\text { kəm-ən } & n ə=n u g-\emptyset \text {-in } \\
\text { sleep-PARTC } & \text { 2SG-be-NON.EGO-SA } \\
\text { 'You (will) sleep!' (BERGQVIST 2012:171) }
\end{array}
$$

A proper interrogative function is found in $-o$, which as a marker of epistemic authority targets the knowledge/experience of the addressee. The example in (5) may be uttered by the speaker when addressing the state of a third person who is expected to be in the focus of the addressee's attention, such as a child, lying in bed in an adjacent room.

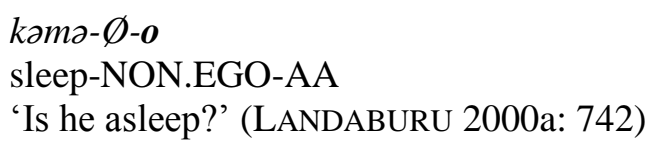

The distribution of -in, $-e$, and -o correlates with the egophoric marker $-w$, which signals the involvement of one of the speech participants and produces a system that partly draws on sentence-type distinctions, but which, at the same time, cannot be accurately accounted for using the notion of sentence-type alone given the effects arising from changes to e.g. subject person (cf. BERGQVIST 2012 for details).

The closely related language Kogi (Arwako-Chibchan; BERGQVIST 2011, forthcoming) has developed an even richer set of markers to signal the speaker's and the addressee's simultaneous perspectives. The form $n i$ - is used in statements that the speaker presents as shared knowledge, while $n a$ - marks knowledge that is exclusive to the speaker.

$$
\begin{array}{lll}
\text { a. } & \text { kwisa-té } & \text { ni-nuk-kú } \\
\text { dance-IMPF } & \text { SPKR.SYM-be.loc-1S } \\
\text { 'I'm dancing (evidently).' (BUN_090824) }
\end{array}
$$

\footnotetext{
2 The difference between examples (2b) and (3) in terms of synthetic vs. auxiliary construction is inconsequential for the proposed analysis of $-e$ as a marker of sentence-type/epistemic authority. The auxiliary nuk is a marker of durative aspect.
} 


\section{b. kwisa-té $\quad$ na-nuk-kú dance-IMPF SPKR.ASYM-be.loc-1S \\ 'I was dancing (not in the moment).' (JM_130613)}

By contrast, shi- is used in utterances where both speaker and addressee are judged to have access to the proposition (7a), from the point of view of the addressee, while sha-is used concerning situations for which the addressee has exclusive knowledge, according to the speaker's assessment (7b).
a. $\quad m a$
kwisa-té
shi-ba-law
2SG.IND dance-IMPF ADR.SYM-2SG-be
'You are dancing (you look like you are)?'
b. nas hanchibé sha-kwísa=tuk-(k)u
1SG.IND good ADR.ASYM-dance=be.loc-1SG
'I am dancing well (in your opinion)?' (BUN_090824)

The prefixes of Kogi epistemic marking are summarized in table 1 to allow for a clearer view of the correspondence between speaker/addressee perspective and the notion of (a)symmetry.

\begin{tabular}{l|l|l}
\hline & Speaker-perspective & Addressee-perspective \\
\hline Symmetric & $n i$ - & shi- \\
\hline & & sha- \\
\hline
\end{tabular}

Table 1. Epistemic prefixes in Kogi (after BERGQVIST forthcoming)

Meaning contrasts that relate to sentence-type distinctions are relevant to the analysis of the Kogi system, albeit differently from markers of epistemic authority in Ika. Bergqvist argues that the use of 'addressee-perspective' instead of 'interrogative' to label the $s h i-/ s h a$ - forms is motivated by the distribution of these forms in narratives, which do not conform to expectation with respect to the function of interrogatives to encourage a reply from an interlocutor. In addition, the interrogative suffix, $-e^{3}$, may not combine with

${ }^{3}$ Possibly cognate to the sentence-type/epistemic authority marker, -e, in Ika. 
the epistemic prefixes, suggesting that all five epistemic prefixes in Kogi, in fact occur in declarative contexts (BERGQVIST forthcoming).

Some evidential systems also harbor semantics that relate to knowledge asymmetries between the speech-participants in referring to events. Jaqaru (Aymaran, Peru; HARDMAN 1986, 2000) has markers that signal evidential contrasts (e.g. direct perception), but also forms like -ishi, which mark facts that are "directly within the personal knowledge of speaker and hearer", partly contrasting with other markers such as $-s k$ "' $a$ that "mock[s] another's assertion of person knowledge with contrary personal knowledge of one's own" (HARDMAN 1986:122).

The Amazonian language Southern Nambikwara (Nambikwaran, Brazil; KROEKER 2001; LOWE 1999) displays a "verificational" contrast between "individual" and "collective" observation (KROEKER 2001: 24pp). In Southern Nambikwara, markers expressing these notions are separate from tense and evidential morphemes and occupy a slot in the inflectional morphology:

a. $\quad w a^{3} k o n^{3}-\emptyset-\emptyset-n a^{2}-l a^{2}$

work-3SG-T/E-IO-PERF

'He worked today (I saw it, but you didn't)' (KROEKER 2001: 88, ex 300 [my adjusted glossing])

b. $\quad w a^{3} k o n^{3}-\emptyset-t a i t^{1}-t i^{2} t u^{3}-w a^{2}$ work-3SG-OA.MIDP-COL-PERF

'He worked (we saw both saw it)' (LowE 1999: 276 [my adjusted glossing])

Yet another kind of system is found in Angal (Wola, Papua New Guinea; SILLITOE 2010), where tense forms with evidential connotations additionally specify the knowledge configuration of the speaker and the addressee with reference to past events/times: "These are the tenses people use to talk definitively about what they and others know" (17). Meaning contrasts relating to speaker-addressee knowledge are: 1) witnessed by both speaker and hearer; 2) witnessed by either the speaker or hearer; 3) not witnessed by the hearer (but heard of previously); 4) not witnessed by the speaker; 5) not witnessed by the speaker nor the hearer (18). These witness-configurations give interesting results, such as talking of events "that they [i.e. the speaker and the addressee] or the listener understand they participated in but cannot remember doing so." (19). Such a case is exemplified in example (9) below: 


$$
\begin{array}{ll}
\text { ibiy } & \text { ba-biysaenda } \\
\text { 2DUAL } & \text { do-REC.PST.hearer(s)_did_not_witness }
\end{array}
$$

'You both did, recently [although you cannot recall it].' (SILLITOE 2010:18-19 [my glossing])

The examples discussed above specify the perspective(s) of the speaker and/or the addressee, which appear to be the focus of epistemic multiple perspective expressions, cross-linguistically. However, there are also examples of multiple perspective epistemics where the viewpoint of the speaker is expressed in combination with a third person or even an unspecified party. Nick Evans provides a nice example of this from the language Dalabon (Gunwinyguan, Australia), which has a form, molkkûn(h) that signals an event as being "unknown to some unspecified person who one would expect to know", e.g. the speaker at some prior moment:

\author{
Deh-molkkunh-bo-ng \\ 2diff.sides.Assert-unknown-go-PST.PERF \\ mak yila-bengkey. \\ NEG 1pl-know.IRR \\ 'You two came here yesterday, without letting us know, we didn't know it.' \\ (EvANS 2005: 95)
}

According to Evans, molkkûn( $h$ ) encodes the speaker's assertion about some state of affairs while also asserting that someone else does not know about the same state of affairs. The identity of that other person is not indicated by molkkûn( $h)$ but must be retrieved from the context.

\title{
3. Issues of analysis
}

Two analytical issues stand out as especially important in the exploration of perspective in epistemic marking, namely the scope properties of forms and their semantic status in terms of membership to some domain of meaning. Scope is primarily an indicator of grammatical status, but with obvious semantic correlates that are used to define the scope properties of a form (cf. BOYE 2012). Several of the discussed forms, especially the modal particles and the sentence-type-like markers (e.g. the SFPs; see section 2.2, above), possess a clear function as modifiers of the speech-act and serve to mitigate the speaker's communicative intentions to make them less intrusive to the addressee (see HOLMES 1984; JACOBS 1991; WALTEREIT 2001). Following the cross-linguistically attested formfunction correspondence tendencies found with grammatical operators of tense, aspect, mood, evidentiality, and illocutionary force (e.g. VAN VALIN \& LA POLLA 1997), there is a candidate slot for speech-act modifiers at the edge of the clause, a position that is iconic to the wide scope properties of such markers. Essentially, a form that has wide scope properties interacts very weakly with the propositional content of a clause and 
remains unaffected by changes to other categorical markers that have a more narrow scope. An increasing number of descriptions attempt to define the scope properties of evidentials in separate languages arguing that some languages have evidentials that display wide scope properties, making them "illocutionary" modifiers, whereas other evidentials have a narrower scope and operate on the propositional level (see FALLER 2002; MURRAY 2011; but see BOYE 2012, for an opposing view).

KOCKELMAN (2004) discusses the classification of complement taking predicates in Q'eqchi' (e.g. predicates of perception, cognition, and psychological states) and proposes a classification according to scope criteria in terms of how well the "commitment event" (instantiated by the complement taking predicate, e.g. say, want, think) maps onto the narrated event (instantiated by the complement). A wider scope, i.e. one that is relatively unaffected by other grammatical features/functions and has little influence on the propositional content of an utterance, is reflected by a looser connection between the complement taking predicate and the complement (e.g. I saw that you took the bike to work) where both parts of the clause are finite, featuring different subjects. A more narrow scope is found with complement taking predicates that are grammatically tighter with the complement (e.g. I want to take the bike to work; KOCKELMAN 2004: 141) where the complement is non-finite and obligatorily has the same subject person as the complement taking predicate. Although complement taking predicates with evidential meaning may not, by default, be equated with evidentials in languages that feature categorical evidentiality, it is possible to apply a similar analysis to such forms (see HENGEVELD \& DALL'AGLIO HATTNHER submitted).

The meaning components of forms harboring multiple perspective semantics are not easy to pinpoint. Interactional aspects of meaning may be difficult to separate from other notions, such as time, which may also co-exist in forms. In addition to expressing the (epistemic) perspective of the speech participants, the speaker's attitude and beliefs may also play an independent role in the adoption of a certain perspective. Despite these difficulties, the notion of 'knowledge asymmetry' appears to have special significance for analyzing the "core" meaning of several of the forms discussed above. This is because 'shared knowledge' (i.e. knowledge symmetry) appears to be a key feature to many forms; the exclusive point of view of the speaker in an epistemic sense (knowledge asymmetry) requires no explanation unless it is contrasted with a form that includes a second point of view. Ad hoc, one would expect that the "exclusive" form is the baseline from which other symmetry-configurations are calculated. This scenario corresponds to how sentence-type is marked by means of sentence final particles where declaratives often are zero and any alteration to the declarative sentence-type is explicitly signaled by the addition of e.g. an interrogative particle. Aside from asymmetries between the knowledge of the speaker and the addressee, there may also be differences in which perspective receives emphasis, the speaker's or the addressee's. In the comparison of modal particles to sentence final particles (SFPs; see Section 2.2, above), this perspectival emphasis becomes relevant given the focus on the speaker's perspective in modal particles, which 
by and large occur in declarative contexts, and the corresponding SPFs that emphasize more the addressee's perspective in interrogative contexts. In Kogi, both knowledge (a)symmetries and perspectival focus must be considered in the analysis of forms (see Section 2.2, above).

At this preliminary stage of investigation, it not clear what effect the grammatical status of forms have on their semantics. Generally, inflectional status means that less context specific calculation is required than with a non-obligatory particle at the edge of the clause, which is used depending on contextual specifics. It is quite probable that some forms that are analyzed as encoding the addressee's perspective are more ad hoc in qualifying information as "generally available" and by implicature signal availability to the addressee as well. In such expressions, it is not clear if the signaled knowledge asymmetries should be regarded as a property of the indexical ground (i.e. the speakeraddressee configuration) or if they are a feature of the figure-ground relationship (i.e. focusing on the quality of the event) and in this sense correspond more to tense-aspect markers than to speech-act modifiers (see above). The semantic richness of a form may also be different with less semantic complexity in inflectional forms, e.g. reducible to an individual/collective contrast, and a richer set of meaning components in forms such as the Jaqaru data source suffix, $-s k$ "' $a$, that "mock[s] another's assertion of personal knowledge with contrary personal knowledge of one's own" (HARDMAN 1986: 122; see Section 2.2, above). However, depending on the grammatical status of the forms in Angal, as discussed in Section 2.2, this need not be the case.

From a methodological stand point, it is important to investigate the effect that utterances featuring multiple perspective forms have on interactive exchanges and how the speech participants position themselves in the ongoing discourse. In many cases, there is a clear patterning of responses against the use of certain forms, something that has been noted by conversation analysts in investigating the form-function correspondence between sentence-type and communicative intentions (e.g. HERITAGE 2012, see Section 4 , below). Other considerations in the investigation of forms are ones that apply to any part of grammar that specifically evokes an ego, i.e. expressions that are indexical and/or evaluative, such as deictics and attitudinal markers. These "shifters" (see JAKOBSON 1990 [1957]) serve to position and situate the ego-centric perspective of the speaker-subject and may sometimes also accommodate the perspective of another to produce a secondary point of reference that coexists with the speaker's own. This embedded perspective is subordinate to the speaker's primary perspective with differences in meaning status e.g. along an implicature-entailment continuum. 


\section{Conclusion}

The notion of multiple perspective in an epistemic sense, evokes the intersubjective underpinnings of language and must be approached from an interactional point of view. In many respects, the properties of the forms exemplified and discussed above are identical to definitions of devices for stance-taking. These feature the speaker's personal belief/attitude/evaluation of public acts that are also subject to the evaluation of others. Additionally, there are relational and interactional components, where the adoption of a stance has consequences for the speaker who adopts it (see ENGELBRETSON 2007: 14).

In the ongoing exploration of forms like the ones discussed above, it is useful to keep a contrast between (moment-to-moment) epistemic stance and (conventionalized) epistemic status (HERITAGE 2012) in mind given the diverse nature of forms that appear to encode (or imply) assumptions concerning (a)symmetrical access to knowledge. While such (a)symmetries are mostly centered around the speaker-addressee origo, they may also involve unspecified third parties, which may or may not include the addressee. It is possible that the distinction between the notions of epistemic status and stance is connected to differences in grammatical form and whether a form is analyzed as inflectional or particle-like. There is a strong expectation for grammaticalized resources in language to be semantically "distilled" compared to lexical means that attend to a corresponding semantic domain. In the case of epistemic perspective, an important concern is to explore what aspects of belief, knowledge, expectation, opinion, and attitude are subject to semantic "reduction" in this sense.

From the discussion so far, a focus on the notion of 'knowledge asymmetry' appears motivated although this concept is subject to subtle modifications as signaled by related notions such as 'epistemic authority', and the idea of "epistemic gradient" as discussed by Enfield et al. (2013; see Section 2.2, above). From an interactional point of view, it appears impossible to reduce the occurrence of the discussed forms to keeping track of what others know; the discussed forms equally have to do with the speaker's communicative goals and intentions, which is why the notion of speech-act modification has some relevance in the discussion of underlying functional motivations of forms.

It is our hope that this collection of papers may stimulate thinking about these and related issues and help to strengthen and diversify the cross-linguistic understanding of epistemic perspective(s) by mapping out important properties and features in the comparison of data from diverse languages. 


\begin{abstract}
Abbreviations
1, first person; 2, second person; 3, third person; AA, addressee authority; ADR, addressee; ASYM, asymmetry; COL, collective; COP, copula; DAT, dative; DBT, doubt; DECL, declarative; DEM, demonstrative; DIR, directional; DIST, distal; DUAL, dualis; EGO, egophoric; EMPH, emphatic; ERG, ergative; FUT, future; IMPF, imperfective; IND, independent; INTERR, interrogative; IO, individual observation; IRR, irrealis; MP, modal particle; MIDP, mid past; NEG, negative; NON.EGO, non-egophoric; OA, observed action; PARTC, participle; PERF, perfective; PROX, proximate; PST, past; QP, question particle; REC, recent; S, singular; SA, speaker authority; S/AA, speakeraddressee authority; SPKR, speaker; SUSP, suspensive; SYM, symmetry; T/E, tenseevidential; Y/N, polar question
\end{abstract}

\title{
References
}

ABRAHAM, WERnER \& EliSABETH LEISS (eds.) (2012): Modality and Theory of Mind Elements across Languages. Trends in Linguistics Studies and Monographs 243. Berlin: Walter de Gruyter.

ANDVIK, ERIK E. (1992): A Pragmatic Analysis of Norwegian Modal Particles. Summer Institute of Linguistics and The University of Texas at Arlington.

BENVENISTE, ÉMILE. (1971) [1966]: Problems in General Linguistics. University of Miami Press, Coral Gables.

BERGQVIST, HENRIK. (2009): The categorical expression of epistemic intersubjectivity in grammar: towards a typology. Presentation at the Chronos 9 international conference on tense, aspect, and modality. September 2-4, 2009, University Paris-Diderot - Paris 7 \& University of Chicago Center in Paris.

BERGQVIST, HENRIK. (2011): Complex perspectives in Arwako languages: comparing epistemic marking in Kogi and Ika. In Austin, PETER K. \& Oliver BOND \& DAVID NATHAN \& LUTZ MARTEN (eds), Proceedings of Conference on Language Documentation \& Linguistic Theory 3. London: SOAS. 49-57.

BERGQVIST, HENRIK (2012): Epistemic marking in Ika (Arwako). Studies in Language (News from the field) 36:1. Amsterdam: John Benjamins 151-178.

BERGQVIST, HENRIK. (2016): Complex epistemic perspective in Kogi (Arwako). International Journal of American Linguistics, 82:1, 1-34.

BOYE, KASPER. (2012): Epistemic meaning: A crosslinguistic and functional-cognitive study. Empirical Approaches to Language Typology 43, Berlin: Mouton de Gruyter.

BURENHULT, NICLAS. (2003): Attention, accessibility, and the addressee: The case of the Jahai demonstrative ton. Pragmatics, 13:3, 363-379.

CAUDAL, PATRICK. AND LAURENT ROUSSAIRE. (2005): Aspectual viewpoints, speech act functions and discourse structure. In KEMPCHINSKY, PAULA AND ROUMYANA SLABAKOVA. (eds.) Aspectual Inquiries. Dordrecht: Springer. 265-290.

CHAFE, WALlaCE AND JOHANNA NiCHOLS. (1986): Evidentiality: the linguistic coding of epistemology. Norwood N.J.:Ablex Pub. Corp. 
Clark, Herbert H. (1996): Using language. Cambridge: Cambridge University Press. CREISSELS, DENIS. (2008): Person variation in Akhvakh verb morphology: functional motivation and origin of an uncommon pattern. STUF, Berlin 61: 4, 309-325.

DANCYGIER, BARBARA \& EVE SWEETSER. (2012): Viewpoint in Language: A multimodal perspective. Cambridge University Press.

ENFIELD, NICHOLAS J. (2003): The definition of WHAT-d'you-call-it: Semantics and pragmatics of 'recognitional deixis'. Journal of Pragmatics 35:1, 101-117.

EnField, Nicholas J., Penelope Brown, Jan P. DE RUITER. (2013): Epistemic dimensions of polar questions: sentence final particles in comparative perspective. In JAN P. DE RUITER (ed.) Questions: Formal, Functional and Interactional Perspectives. Cambridge University Publishing Online. 193-221

ENGLEBRETSON, ROBERT (2007): Stancetaking in Discourse. Pragmatics \& Beyond New Series 164. Amsterdam/Philadelphia: John Benjamins.

EVANS, NichOLAS. (2005): View with a view: towards a typology of multiple perspective. Berkeley Linguistics Society 31: 93-120.

FALLER, MARTINA. (2002): Semantics and Pragmatics of Evidentials in Cuzco Quechua. $\mathrm{PhD}$ dissertation. Stanford University.

FAUCONNIER, GILlES. (1985): Mental Spaces. Cambridge, Mass.: MIT Press.

Fleischman, SuZANNE (1991): Toward A Theory of Tense-Aspect in Narrative Discourse. In J. GVOZDANOVIC \& T. JANSSEN (eds.), in co-operation with ÖSTEN DAHL, The Function of Tense in Texts. Amsterdam: North Holland, 75-97.

GofFMAN, ERVING. (1981): Forms of Talk. Philadelphia: University of Philadelphia Press.

HADDAD, Youssef A. (2013): Pronouns and intersubjectivity in Lebanese Arabic gossip. Journal of Pragmatics 49: 57-77.

HAle, AUSTIN. (1980): Person markers: finite conjunct and disjunct forms in Newari. In Trail R. (ed.) Papers in Southeast Asian Linguistics 7. Canberra: Pacific Linguistics. 95106.

HARDMAN, MARTHA JAMES. (1986): Data-Source Marking in the Jaqi Languages. In CHAFE; WALlaCE AND JOHANNA NiCHOLS (eds.) Evidentiality: the linguistic coding of epistemology. Norwood N.J.:Ablex Pub. Corp. 113-136.

HARDMAN, MARTHA JAMES. (2000): Jaqaru. Languages of the World/Materials 183. Munchen: LINCOM EUROPA.

HENGEVElD, KeES \& MARIZE MATTOS DALl'AgLio HATTNHER. (submitted): Four types of evidentiality in the native languages of Brazil.

http://home.hum.uva.nl/oz/hengeveldp/publications/subm_hengeveld\&mattos_dall\%27a glio_hattnher.pdf

HeRITAge, JoHN. (2012): Epistemics in Action: Action Formation and Territories of Knowledge. Research on Language \& Social Interaction 45, Routledge. 1-29.

HeRITAGE, JOHN. (2013): Epistemics in Conversation. The Handbook of Conversation Analysis. Blackwell Publishing. 370-394. 
Heritage, John \& GeOFFREY RAYMOND. (2005): The Terms of Agreement: Indexing Epistemic Authority and Subordination in Assessment Sequences. Social Psychology Quarterly 68: 15-38.

HIMMELMANN, NiKOLAUS. (1996): Demonstratives in narrative discourse: a taxonomy of universal uses. In BARBARA FOX (ed.), Studies in anaphora . Amsterdam: Benjamins.205-254.

HINDS, JOHN. (1973): Some remarks on soo su-. Papers in Japanese Linguistics: 18-30 HOLMES, JANET. (1984): Modifying illocutionary force. Journal of Pragmatics 8: 345365, Elsevier.

HOPPER, PAUL J. (1979): Some Observations on the Typology of Focus and Aspect in Narrative Language. Studies in Language 3:1, 37-64.

JACOBS, JOACHIM. (1991): On the semantics of modal particles. In Abraham, Werner (ed.) Discourse particles: descriptive and theoretical investigations on the logical, syntactic, and pragmatic properties of discourse particles in German. Pragmatics and beyond. Amsterdam: John Benjamins. 141-163.

JAKOBSON, ROMAN. (1990) [1957]. Shifters and Verbal Categories. In LINDA R. WAUGH AND Monique MonviLle-Burston (eds.). On Language. Cambridge, MA: Harvard UP. 386-392.

KoCKELMAN, PAUL. (2004): Stance and Subjectivity. Journal of Linguistic Anthropology 14, 127-150.

Kroeker, MEnNo. (2001): A Descriptive Grammar of Nambikuara. International Journal of American Linguistics 67:1, 1-87. Chicago: University of Chicago.

KÖNIG, EKKEHART, DETLEF STARK \& SUSANNE REQUARDT. (1990): Adverbien und Partikeln. Ein deutsch-englisches Wörterbuch. Heidelberg: Julius Groos Verlag. LABOV, WiLliam \& DAVID FANSHEL. (1977): Theraputic Discourse: Psychotherapy as Conversation. New York: Academic Press.

LANDABURU, JON. (2000): La lengua ika. In Lenguas indígenas de Colombia : una visión descriptiva. Bogota: Instituto Caro y Cuervo.

LANDABURU, JON. (2007): La modalisation du savoir en langue Andoke (Amazonie Colombienne). In GUENTCHÉVA, ZLATKA AND JON LANDABURU (eds.) L'eénonciation médiatisée II - Le traitment épistémologique de l'information: illustrations amérindiennes et caucasiennes. Paris: Éditions Peeters.

LEVINSON, STEPHEN. C. (1979): Activity types and language. Linguistics 17, 365-399.

LEVInson, STEPHEN. C. (1983): Pragmatics. Cambridge: Cambridge University Press. LINDSTRÖM, JAN. (2008): Tur och ordning. Introduktion till svensk samtalsgrammatik. Stockholm: Norstedts.

LOWE, IVAN. (1999): Nambiquara. In DiXon, R.M.W. \& ALEXANDRA Y. AikHENWALD (eds.) The Amazonian Languages. Cambridge: Cambridge University Press. 269-291. LyONS, JOHN. (1977): Semantics, vol. 2. Cambridge: Cambridge University Press. MURRAY, SARAH. (2010): Evidentiality and the structure of speech acts. PhD dissertation. Rutgers: New Jersey. 
Mushin, ILANA. (2001): Discourse Analysis: Evidentiality and Epistemological Stance: Narrative Retelling. Amsterdam: John Benjamins Publishing Company.

SAN RoQUe, LILA. (2008): An Introduction to Duna Grammar. PhD dissertation, Canberra: Australian National University.

SAN RoQue, Lila, SimeOn Floyd AND Elisabeth NORClifFe. (forthcoming): Evidentiality and interrogativity. Amsterdam: John Benjamins.

Sillitoe, PAUl. (2010): Trust in development: some implications of knowing in indigenous knowledge. Journal of the Royal Anthropological Institute 16: 12-30. Wiley Online Library.

SMith, CARLOTA S. (1991): The Parameter of Aspect. Dordrecht: Kluwer.

SEARLE, JOHN R. (1969): Speech Acts: An essay in the philosophy of language. Cambridge: Cambridge University Press.

SimON-VANDENBERGEN, ANNE-MARIE \& KARIN AIJMER. (2007): The Semantic Field of Modal Certainty: A Corpus-Based Study of English Adverbs. Berlin: Mouton de Gruyter. STIVERS, TANYA. (2010): An overview of the question-response system in American English conversation. Journal of Pragmatics. 42:10, 2772-2781.

TRAUGOTT, EliSABETH. (1989): On the rise of epistemic meanings in English: An example of subjectification in semantic change, Language 57: 33-65.

TraugotT, Elisabeth Closs \& Richard B. DASHER. (2002): Regularity in Semantic Change. Cambridge: Cambridge University Press.

VAN VAlin, RoBert D. \& RANDY J. LAPOLlA. (1997): Syntax: Structure, Meaning, and Function. Cambridge: Cambridge University Press.

WALTEREIT, RICHARD. (2001): Modal particles and their functional equivalents: a speech-act-theoretic approach. Journal of Pragmatics 33: 1391-1418.

Henrik Bergqvist

Department of Linguistics

Stockholm University

henrik.bergqvist@ling.su.se 